\title{
A AUTONOMIA COMO ESTRATÉGIA POLÍTICA E TERRITORIAL ENTRE OS MOVIMENTOS SOCIAIS NO BRASIL: ENTREVISTA COM A TEIA DOS POVOS DA BAHIA
}

\author{
AUTONOMY AS A POLITICAL AND TERRITORIAL STRATEGY AMONG SOCIAL \\ MOVEMENTS IN BRAZIL: INTERVIEW WITH TEIA DOS POVOS DA BAHIA

\section{LA AUTONOMÍA COMO ESTRATEGIA POLÍTICA Y TERRITORIAL ENTRE LOS} \\ MOVIMIENTOS SOCIALES DE BRASIL: ENTREVISTA CON LA TEIA DOS POVOS DA \\ BAHIA
}

Fábio Márcio Alkmin ${ }^{1}$ https://orcid.org/0000-0001-5115-5916

Waldo Lao Fuentes Sánchez² https://orcid.org/0000-0001-9308-524X

\footnotetext{
${ }^{1}$ Geógrafo e doutorando no Programa de Pós-graduação em Geografia Humana, na Universidade de São Paulo. Desenvolve pesquisa sobre autonomias indígenas na América Latina, com apoio da Fundação de Amparo à Pesquisa do Estado de São Paulo (FAPESP), processo no 2018/22226-4, e da Coordenação de Aperfeiçoamento de Pessoal de Nível Superior - Brasil (CAPES) - Código de Financiamento 001. E-mail: fabiogeo@usp.br

${ }^{2}$ Possui graduação em Etnología pela Escuela Nacional de Antropología e História - ENAH. Mestre e Doutor pelo Programa de PósGraduação em Integração da América Latina da Universidade de São Paulo - PROLAM/USP. Áreas de interesse: Movimentos Sociais na América Latina, Autonomia Indígena e Comunicação Alternativa. E-mail: waldolao@gmail.com
}

\section{RESUMO}

As organizações indígenas na América Latina vêm cada vez mais desenvolvendo estratégias de autonomia como forma de autodeterminação e defesa de seus territórios. Ainda que com grandes particularidades locais e regionais, a autonomia enquanto práxis destes povos busca basicamente a organização das comunidades a partir de mecanismos de territorialização e autogoverno, criando sistemas horizontais de deliberação política e apoio mútuo, além de formas de sociabilização autônomas às influências dos partidos políticos ou da tutela do Estado. O presente artigo busca oferecer uma reflexão sobre a autonomia no contexto brasileiro, a partir de uma entrevista com a Teia dos Povos da Bahia, articulação criada em 2012 pela união de indígenas, quilombolas e distintos movimentos camponeses que lutam pela terra e território no país.

Palavras-chave: Território. Autonomia. Povos Indígenas. Quilombolas. Camponeses.

\begin{abstract}
Indigenous organizations in Latin America more and more commonly develop strategies of autonomy as a form of self-determination and defense of their territories. With vast particularities both local and regional, autonomy as practiced by these groups, seeks to reorganize communities through mechanisms of territoriality and self-governance, creating horizontal systems of political decision-
\end{abstract}


making and mutual support, as well as autonomous ways of socialization outside of the influence of political parties and the supervision of the State. The present article reflects on autonomy in the Brazilian context through an interview with Teia dos Povos da Bahia, founded in 2012 from the union of indigenous peoples, quilombolas, and different rural movements fighting for land and territory in the country.

Keywords: Territory. Autonomy. Indigenous People. Quilombolas. Peasantes.

\section{RESUMEN}

Las organizaciones indígenas en América Latina, cada vez mas desarrollan estrategias de autonomía como forma de autodeterminación y defensa de sus territorios. Mismo que con grandes particularidades tanto locales como regionales, la autonomía en tanto una praxis de estos pueblos busca la re-organización de las comunidades a partir de mecanismos de territorialización y autogobierno, creando sistemas horizontales de decisión política y apoyo mutuo, además de formas de socialización autónomas fuera de las influencias de los partidos políticos o de la tutela del Estado. El presente articulo pretende ofrecer una reflexión sobre la autonomía en el contexto brasileño, a partir de una entrevista realizada con la Teia dos Povos da Bahia, articulación creada en 2012 pela unión de indígenas, quilombolas y distintos movimientos campesinos que luchan por la tierra y territorio en el país.

Palabras clave: Território. Autonomia. Pueblos Indígenas. Quilombolas. Campesinos.

\section{INTRODUÇÃO}

"Não acreditamos mais na possibilidade de solucionar o problema dos povos, combater a miséria, a desigualdade e as violências por meio das engrenagens do Estado". “Também não acreditamos que haverá um pacto democrático e popular para assegurar direitos fundamentais para a classe trabalhadora". "Ter autonomia é entender que o Estado é racista, patriarcal e burguês". Com estas e outras reflexões críticas a Articulação Teia dos Povos vem buscando tecer novas formas de atuação política no campo brasileiro, unindo a luta de indígenas, quilombolas e camponeses no país.

Conforme registrado no livro "Por terra e território: caminhos da revolução dos povos no Brasil” (FERREIRA; FELÍCIO, 2021), uma espécie de postulado teórico e manual prático de organização, o objetivo estratégico da articulação - ou a "grande jornada" como preferem dizer - é o fim do capitalismo, do racismo e do patriarcado, a partir de uma grande "Aliança Preta, Indígena e Popular" (Ibidem, p.38). Mas, como explicam, esta luta assim posta é muito teórica e abstrata, dificultando a unidade política necessária para tais enfrentamentos. Uma jornada sempre começa com a "caminhada", algo menor e cotidiano: desta forma, a Teia dos Povos defende que para se vencer o capitalismo é necessário antes ter água potável acessível, comida sem veneno no prato, o corpo forte para os combates. Assim, a articulação caminha 
criando bancos de semente crioula, plantando comida agroecológica e cuidando das fontes de água, entre outras frentes de atuação, como a criação de escolas e grupos de autodefesa. Ou seja, é na ação concreta, material, territorializada e autônoma que a organização fundamenta sua ação.

No entanto, como advertem, a autonomia não é autossuficiência ou isolamento, pelo contrário, é a aliança entre diversos territórios em resistência, que se fortalecem, se apoiam e se complementam, ao modo de uma federação:

Quando falamos em territórios autônomos, não estamos falando que aquele espaço produz $100 \%$ dos bens necessários para manter a vida ali. Ainda que experiências assim existam, em um mundo cada vez mais dinâmico e conectado, entendemos que autonomia é ter condições de acessar bens provenientes do trabalho realizado em outros territórios, mas a partir de uma rede de atuação conjunta (Ibidem, p.51).

Dessa maneira, a luta por autonomia diz respeito ao direito de ser e permanecer diferente, criando-se estruturas de poder popular, onde as decisões são coletivas e os projetos na medida do possível são autofinanciados:

Ter autonomia é entender que o Estado é racista, patriarcal e é burguês. Qualquer processo de inclusão não transformará seu fundamento, mas certamente afastará o povo de sua real dignidade, que se expressa na face erguida de quem não precisa pedir nada a ninguém. Essa falsa inclusão também afasta uma parcela do povo de uma reflexão verdadeiramente crítica e rebelde. Sim, as políticas públicas cativam os de baixo em um conformismo mediante a dependência do Estado - diríamos mais, a uma dependência dos governos ditos progressistas. (Ibidem, p.52)

Na América Latina, tal distanciamento das estruturas do Estado e do sistema de representação partidária vem crescendo desde os anos 1990, em especial entre os povos indígenas, que lançam mão dessa estratégia como forma de defesa territorial e garantia de direitos políticos e culturais.

No México, por exemplo, podemos citar o Exército Zapatista de Libertação Nacional, no estado de Chiapas; o autogoverno de Cherán, no estado de Michoacán ou ainda a Polícia Comunitária Indígena, no estado de Guerrero. Já na América do Sul, podemos citar o Governo Territorial Autônomo Wampi, na Amazônia peruana; os povos Kichwa de Sarayaku, no Equador; o Conselho Indígena Regional de Cauca (CRIC), na Colômbia; a Guarda Indígena da Comunidade Whasek Wichi, no Chaco (norte da Argentina) ou ainda a reconstrução autônoma das comunidades Mapuche, no Chile e na Argentina. 
No Brasil, particularmente, isso não poderia ser diferente. A autonomia no país vem sendo construída pelos povos indígenas de diversas formas, sempre a partir do protagonismo e poder dos povos nos territórios. Entre a pluralidade destas estratégias autonômicas podemos citar, apenas como alguns exemplos: as autodemarcações territoriais, como a dos Munduruku no Pará; as retomadas, como a dos Tupinambá na Bahia; os grupos de vigilância e autodefesa, com a dos Guajajara, Ka'apor e Awá Guajá no Maranhão; os Protocolos de Consulta Prévia, criados por diversos povos indígenas nos últimos anos ou ainda as estratégias de territorialização em rede, da Teia dos Povos, acima descrita brevemente. Estas expressões demonstram que a autonomia vem sendo uma maneira que os povos mais radicalizados vêm encontrando para enfrentar as tensões, violências e injustiças cometidas pelo Estado em seu processo de submetimento e espoliação.

Como forma de aprofundarmos o debate sobre este tema no Brasil, convidamos a Teia dos Povos da Bahia a nos conceder uma entrevista, pedido o qual foi gentilmente atendido em abril de 2021. Desejamos a todas e todos uma boa leitura!

\section{1) Olá, muito obrigado pela entrevista. Por favor, você pode nos dizer o que é a Teia dos}

\section{Povos?}

A Teia dos Povos é uma articulação de comunidades, povos, territórios e organizações em luta por Terra e Território. Ou seja, não somos uma organização política em si, mas uma experiência de rede, de federação, de comunidade dos diferentes em uma luta maior para conquistar autonomia para os territórios. Ou seja, há diferentes experiências de lutas dentro da Teia. Há quem esteja trabalhando sua autonomia desde os fundamentos mais radicais e há quem paute o Estado como possibilidade de emancipação. A unidade aqui se dá na prática, na ação concreta, comunitária, nos mutirões. O que nos une é maior do que o que nos separa. A frase atribuída ao Milton Santos nos aquece para construir uma grande jornada de luta com tempos diferentes das caminhadas.

\section{2) Como nasceu a Teia dos Povos?}

Ela surgiu em 2012, na Jornada de Agroecologia da Bahia, no Assentamento Terra Vista (MST), no município de Arataca (Bahia), num encontro que reuniu Pataxó, Pataxó Hãhã-hãe, Tupinambá, quilombolas e distintos movimentos campesinos. Na origem tratava-se de uma rede para a Agroecologia, para difundir as sementes crioulas, mas já existia uma perspectiva territorial e de enfrentamento com o capitalismo, contudo nos últimos anos o 
caminho da autonomia foi se consolidando frente às reflexões sobre nossa história. Após a $5^{\mathrm{a}}$ Jornada em Porto Seguro a articulação começou a buscar expandir a aliança aos movimentos urbanos, e hoje já conta com MSTB (sem-teto) e quilombistas periféricos como a Reaja Ou Será Mort@. Como a Teia, seus nascimentos são muitos e seguem ocorrendo. Enquanto escrevemos nasce uma Teia no Rio Grande do Sul e uma no Ceará. Ainda há outro nascimento anterior à própria articulação na Bahia que é a Teia dos Povos e Comunidades Tradicionais do Maranhão, uma Teia irmã que segue uma caminhada muito própria, mas irmanando as mesmas lutas.

\section{3) Como a Teia dos Povos está organizada? Com toda a diversidade dos grupos, como conseguem unificar as lutas?}

O principal fundamento de organização é a divisão da articulação entre quem é Núcleo de Base e quem é Elo da Teia. Os Núcleos de Base são os territórios, ou seja, comunidades, povos, organizações que disputem a territorialidade. O quilombo da Lagoa Grande em Feira de Santana, por exemplo, é um Núcleo de Base, ou o Assentamento Terra de Santa Cruz, em Santa Luzia, porque ali vivem pessoas, porque possuem uma comunidade organizada e participam nas atividades como coletivo que está no chão, na terra. Já o Elo da Teia é uma organização ou coletivo de sujeitos desterritorializados, gente que não organiza uma comunidade, que não estão lidando com a terra, nem participando diretamente de retomada, nem construindo uma territorialidade própria. Assim, um coletivo de estudantes como o GAIA da UFRB, um grupo de pesquisa como o Autonomias da UFSB ou uma associação de advogados como AATR, participam da Teia como Elos da Teia.

Na Teia dos Povos a política territorial, a direção das lutas, só pode ser definida pelos Núcleos de Base. Os Elos da Teia participam opinando, mas não podem determinar a caminhada estratégica. Podem dizer dentro das táticas como podem ajudar, mas não dirigir a rede. Este foi um mecanismo para que caminhada não seja tomada por intelectuais das classes médias que quase sempre acabam por suplantar as lideranças de base. Mais do que isso, partese do pressuposto que pode construir uma nova sociedade quem já saiba pelo menos organizar uma comunidade. Como alguém que nunca lidou com as dificuldades da vida comunitária poderá liderar a construção de uma sociedade baseada na autonomia dos territórios? Então, antes de pautar como será a luta, é preciso aprender a construir comunidades.

\section{4) Vocês trabalham em torno de conceitos como "terra", "território" e "autonomia". O que significam e por que são importantes?}


A Terra é a base da vida humana. Sem o controle e a posse da terra é impossível ter qualquer esperança de fim ou diminuição da desigualdade. O latifúndio é nosso mais longevo inimigo, então romper com seu poder, significa a retomada da terra.

O Território é aquilo que está para além da cerca. Então quando um movimento campesino retoma uma fazenda, aquilo ainda é uma propriedade fundiária. levará tempo até aquilo se tornar uma comunidade, mas é possível que nunca se torne um território em si, caso aquelas pessoas não compreendam a dimensão do território. Porque o território está para além da demarcação fundiária, pois é o campo simbólico associado à terra, as culturas, a forma de conviver com aquela mata ou aquele rio, com uma serra. Para os povos indígenas isto está mais claro porque estão há tanto tempo naquele chão que reconhecem o tempo que os pássaros vão e vem, sabem dos ventos e das chuvas e até para onde elas vão, conhecem os caminhos que as antas fazem e as plantas preferidas do jupará. Mas para os povos que estão retomando a terra há que ter o território como tarefa ativa de construção, ou seja, significação dos espaços, dos lugares, dos contornos necessários para viver nós, nossas gerações futuras e todos os seres que ali habitam.

Já a autonomia é a forma, o jeito, como caminhamos para a Terra. Nós não queremos nem a tutela do Estado, tampouco o ordenamento dos partidos ou chantagem do mercado. Queremos percorrer este duro caminho com nossas próprias pernas, com nossos acertos e erros como nossas responsabilidades. Uma vez conquistando desta forma, cultivar a autonomia no território é manter a determinação sobre o uso daquela terra, por quem ali vive e trabalha. Significa construir sua forma de educar, suas tecnologias para água, para energia, seus rumos para a sociedade de superação do capitalismo. Isso para nós é a autonomia.

\section{5) $\mathbf{E}$ como vocês vêm construindo as autonomias?}

Os mais velhos e os mais velhos que os nossos mais velhos têm explicado para nós que há que começar tudo pelas águas e pela comida. Então a primeira ação tática de formação da rede foi através da semente. Para além do simbolismo de começar pela semente, pela semente crioula, há aqui um fundamento: qualquer luta que nós vamos travar com o capitalismo, comida será fundamental. Pois não há guerreiras e guerreiros de pé sem a comida, mas também porque através da comida é possível subir florestas, agroflorestas, roças agroecológicas que protegerão a terra da destruição que é esta sociedade do capital. Então nós temos difundido sementes crioulas, subido florestas, organizado retomadas, defendido nossas companheiras e nossos companheiros quando são atacados. 
Hoje sabemos que há uma crise hídrica em muitas partes do país, sobretudo nas periferias. Esta é uma guerra que não se vence nas cidades, mas no campo, levantando floresta, protegendo nascentes, impedindo os megaprojetos destrutivos. E é aí que nossa luta se alarga, pois estamos falando de plantar água, de florestas capazes de gerar riqueza para manter comunidades, mas também gerar comida em abundância, fartura. Então nós temos expandido a Aliança Preta, Indígena e Popular através da retomada da terra, do plantio de florestas, da disseminação de sementes crioulas, da proteção das águas, este tem sido nossa forma de caminhar neste início de jornada.

\section{6) Há experiências autônomas no Brasil ou no plano internacional que servem de inspiração para a Teia dos Povos?}

A luta por autonomia territorial dos povos indígenas sempre foi farol para nossa construção de uma jornada contra o racismo, o capitalismo e o machismo. Certamente a luta por autonomia Mapuche, das Guardias colombianas e de Chiapas nos inspiram. Porém os exemplos mais próximos da Teia do Maranhão ou dos Tupinambá do Sul da Bahia são poderosos. Nós sempre lembramos que os Tupinambá enfrentaram exército, polícia federal e força nacional na década passada, todos levados lá para expulsá-los do território. O Estado perdeu a guerra contra os Tupinambá. Eles seguem lá em seu território ancestral, plantando, colhendo, dançando, cantando, protegendo todos os seres daquele bioma fantástico que é a Mata Atlântica, este jardim dos povos originários.

\section{7) Quais são atualmente as maiores dificuldades para se aprofundar as autonomias?}

Nossos povos não lidam tão bem ainda com o debate sobre autonomia. A verdade é que apesar da maioria dos povos literalmente viver sem amparo ou cuidado digno por parte do Estado nacional, passamos muito tempo com uma política nas esquerdas em que toda luta deveria se encerrar na conquista deste Estado. O pior, um Estado que é de natureza burguesa, racista, que mesmo que alcancemos Brasília, não temos como mudar a natureza dele. Então a regra ainda é disputar o Estado. Quando falamos que não faremos isto, há muita gente que torce o bico, que não gosta. Mas estamos falando com base nas experiências de nossos povos mais rebeldes. Eles enfrentaram o Estado: a Balaiada, Canudos, as cidades santas do Contestado, os malês, a Federação dos Tamoyos... então acreditamos que precisamos aprender com a história que é mais velha ainda que nossos mais velhos. E ela nos tem indicado este caminho. 
Só que a autonomia é uma decisão que nossos acertos e erros pesam sobre nossas costas, não temos ninguém para culpar por nossos eventuais fracassos. E em políticas muitas vezes as pessoas querem alguém para culpar pelos projetos fracassados. Um último aspecto é o trabalho. A terra não gera por si riqueza capaz de enfrentar o capitalismo. Para termos condições de luta grandiosa há que se trabalhar muito, com disciplina, com atenção ao coletivo. E há muita gente que quer lutar, mas não consegue entender que antes de uma grande luta há uma grande roça. Então o tempo do silencioso plantio, o tempo das tarefas sem tradição da política convencional, é menosprezado. Mas este é o fundamento da luta: se não plantamos nossa própria comida, como podemos dizer que vamos construir uma sociedade sem o capital? Então as esquerdas ainda precisam avançar neste aspecto, precisam reconhecer a importância da terra, dos biomas, da vida. Proteger a vida em sua expressão natural é tarefa grandiosa, que não pode ser deixada para depois de se conquistar Brasília, isso é um erro.

\section{8) Ainda sobre as autonomias, vocês diriam que essa estratégia vem se expandindo entre os movimentos sociais? Por quê?}

O que podemos dizer é que sentimos desilusões quanto a estratégia de conquista do Estado através dos partidos. Sentimos muita gente desgastada com a relação com a institucionalidade política, mesmo aquelas organizações ditas revolucionárias. Isto não significa que estão abraçando o caminho da autonomia. Mas há ali e acolá muita gente de dentro dos movimentos sociais dizendo: olha, vocês estão certas, certos, é este o caminho. Os movimentos sociais em si ainda não despertaram para esta questão, mas há muitos militantes ali que já pensam deste jeito, há inclusive dirigentes de base que estão por este caminho, mas a estratégia geral dos movimentos ainda é fazer sinalizações para a política partidária e ser parte da estratégia geral de um ou outro partido. E nós acreditamos que há espaço para tudo neste Brasil imenso. Então não estamos aqui falando que este caminho da institucionalidade é um erro, estamos apenas falando que não mais seguimos por esta via. Sentimos que os povos originários estão expressando atualmente uma palavra de autonomia cada vez mais poderosa, e isto é contagiante, isto é movimento, mobiliza gente de outros movimentos. Assim temos esperança que esta caminhada se amplie.

\section{9) A Teia dos Povos recentemente lançou o livro "Por Terra e Território". Poderia nos falar um pouco sobre? Como é possível adquirir a obra?}

O livro aborda as teses gerais de Mestre Joelson Ferreira, que possui mais de 30 anos de luta no MST e é um dos co-fundadores da Teia dos Povos. Ali se apresenta o sentido da 
terra e território e a escolha do caminho da autonomia. Há no meio do livro um pequeno manual para algumas das soberanias fundamentais na formação dos territórios (hídrica, alimentar, pedagógica, de trabalho e renda, energética...) e uma reflexão mais profunda sobre o cuidado com a militância, o trabalho ativo pela participação e liderança das mulheres e a ancestralidade - que nós diríamos que é a diferença fundamental da forma como a Teia luta nas esquerdas.

O livro foi escrito com a ajuda de Erahsto Felício, um educador da educação básica que, com muitos telefonemas e uma visita ao longo da pandemia, conseguiu ir escrevendo as ideias do mestre. Joelson revisou o texto, mudou, criticou, melhorou a redação e assim surgiu o livro. As teses mostram uma forma de lutar e construir a revolução dos povos do Brasil, discutindo como as esquerdas materialistas interpretaram mal os povos de nosso país e não conseguiram convergir uma luta grandiosa contra o latifúndio, que é o principal fiador de qualquer governo neste país. O livro é adquirido diretamente conosco no site

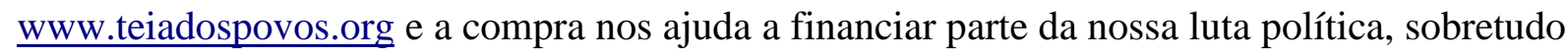
ajuda o Mestre Joelson a seguir falando deste caminho para outras geografias longe da Bahia.

\section{0) Como pesquisadores ou outros(as) interessados(as) podem colaborar com a Teia dos} Povos?

Nós possuímos uma reflexão crítica sobre a participação dos pesquisadores na articulação. Muitas comunidades estão ressabiadas com gente que pesquisa, mas não deixa qualquer contribuição minimamente materializável para a luta. Também por isso que fazemos sempre questão de dizer que o povo dos territórios é que fazem a frente do movimento. Porém os mais velhos também nos dizem que a luta que estamos fazendo é uma luta grandiosa, que sem movimento de massas não há vitória contra o latifúndio. Deste modo, todas e todos podem chegar e se ajuntar nesta grande jornada. Entretanto dizemos aos pesquisadores: vocês precisam perguntar como colaborar, e não acreditar que a colaboração é sua própria pesquisa.

Podemos dar o exemplo do livro: nós não precisamos de alguém para fazer uma pesquisa e publicar um livro, precisamos de pesquisadores que se desalienem das atividades intelectuais e ponham a mão na massa. Há bastante conteúdos, reflexões, conhecimentos nos territórios e entre os povos, mas os pesquisadores topam, para além de escrever sobre isto, produzir um livro, imprimi-lo na gráfica, vender, levar aos correios, checar o e-mail, gerar riqueza com este conhecimento, e não apenas tratar como mera obra intelectual? Outro exemplo: há uma cozinha comunitária sendo erguida numa periferia. Não precisamos de artigos submetidos a revistas sobre a cozinha, mas talvez precisemos de alguém para fazer a 
comunicação cotidiana daquela ação, ou de um cozinheiro, ou de uma motorista para entregar a comida.

A classe média possui muitas habilidades que só foram desenvolvidas porque a sociedade impediu outros e outras de desenvolverem aquelas potencialidades. A classe média, precisa, portanto, retribuir com isso. Se há uma importante fala de um cacique ou de uma mestra tradicional, vocês podem traduzir para que nossos irmãos de outras partes da América Latina nos entendam? Vocês podem usar suas redes para ajudar na proteção de nossos territórios quando são atacados? Podem estar conosco nestes momentos duros? Então não queremos discutir com os pesquisadores enquanto pesquisadores, mas como companheiros e companheiras de luta, é sobre isso nossa aprendizagem nesta relação.

\section{1) Finalmente, há algo que julgue importante que gostaria de agregar à entrevista?}

Sem o conhecimento profundo de nossos povos não é possível construir uma forma de fazer aliança na megadiversidade que existe em nosso país continental. As esquerdas não conhecem os povos, não acreditam em suas cosmovisões, não conversam com os encantados, não escutam os avisos dos voduns. Contudo, as grandes rebeliões deste país tinham um pé na ancestralidade e outro na espiritualidade de nossos povos. Sem aprofundarmos ao ponto de chegar neste campo, a conversa fica sempre carregada por um paternalismo oriundo das tradições anti-capitalistas europeias. Há que romper isto. Há que se aprofundar no conhecimento dos povos, na sabedoria que escondem em suas memórias, nas suas manifestações. Dentro destas cosmovisões estão lições fundamentais para corrigir rumos individuais e coletivos, corrigir vícios e erros políticos que seguimos cometendo. Sem uma boa individualidade, cultivada em bons valores com o coletivo e com a natureza, não existe coletividade poderosa, capaz de vencer o racismo que nos atinge em cheio.

E-mail de contato da Teia dos Povos: terraeterritorio@protonmail.com

\section{REFERÊNCIAS}

FERREIRA, Joelson; FELÍCIO, Erahsto. Por terra e território: caminhos da revolução dos povos no Brasil. Arataca (BA): Teia dos Povos, 2021. 
A autonomia como estratégia política e territorial entre os movimentos sociais no Brasil: entrevista com a Teia dos Povos da Bahia.

Fábio M. Alkmin; Waldo L. F. Sánchez

Artigo recebido em: 29 de junho de 2021.

Artigo aceito em: 02 de agosto de 2021.

Artigo publicado em: 13 de setembro de 2021. 